\title{
BMJ Open Challenges facing essential workers: a cross-sectional survey of the subjective mental health and well-being of New Zealand healthcare and 'other' essential workers during the COVID-19 lockdown
}

\author{
Caroline Bell, ${ }^{1}$ Jonathan Williman, ${ }^{2}$ Ben Beaglehole, ${ }^{1}$ James Stanley (D) , \\ Matthew Jenkins, ${ }^{4}$ Philip Gendall, ${ }^{3}$ Charlene Rapsey, ${ }^{5}$ Susanna Every-Palmer ${ }^{4}$
}

To cite: Bell C, Williman J, Beaglehole B, et al. Challenges facing essential workers: a cross-sectional survey of the subjective mental health and well-being of New Zealand healthcare and 'other' essential workers during the COVID-19 lockdown. BMJ Open 2021;11:e048107. doi:10.1136/ bmjopen-2020-048107

- Prepublication history and additional supplemental material for this paper are available online. To view these files, please visit the journal online. To view these files, please visit the journal online (http://dx.doi. org/10.1136/bmjopen-2020048107).

Received 22 December 2020 Accepted 14 June 2021

Check for updates

(C) Author(s) (or their employer(s)) 2021. Re-use permitted under CC BY-NC. No commercial re-use. See rights and permissions. Published by BMJ.

For numbered affiliations see end of article.

Correspondence to

Dr Caroline Bell;

caroline.bell@otago.ac.nz

\section{ABSTRACT}

Objectives To compare psychological outcomes, experiences and sources of stress over the COVID-19 lockdown in New Zealand in essential workers (healthcare and 'other' essential workers) with that of workers in nonessential work roles.

Design Online cross-sectional survey.

Setting Conducted in New Zealand over level 4 lockdown in April/May 2020.

Participants Findings from employed participants (2495) are included in this report; 381 healthcare workers, 649 'other' essential workers and 1465 nonessential workers. Primary and secondary outcome measures Measures included psychological distress (Kessler Psychological Distress Scale (K10)), anxiety (Generalised Anxiety Disorder (GAD-7)), well-being (WH0-5), alcohol use, subjective experiences and sources of stress. Differences between work categories were quantified as risk ratios or $\chi^{2}$ tests. Results After controlling for confounders that differed between groups of essential and nonessential workers, those in healthcare and those in 'other' essential work were at $71 \%(95 \% \mathrm{Cl} 1.29$ to 2.27$)$ and $59 \%(95 \% \mathrm{Cl}$ 1.25 to 2.02) greater risk respectively, of moderate levels of anxiety (GAD-7 $\geq 10$ ), than those in nonessential work. Those in healthcare were at $19 \%(95 \% \mathrm{Cl} 1.02$ to 1.39$)$ greater risk of poor well-being (WHO-5<13). There was no evidence of differences across work roles in risk for psychological distress $(\mathrm{K} 10 \geq 12)$ or increased alcohol use. Healthcare and 'other' essential workers reported increased workload $(p<0.001)$ and less uncertainty about finances and employment than those in nonessential work $(p<0.001)$. Healthcare and nonessential workers reported decreased social contact. No difference by work category in health concerns was reported; $15 \%$ had concerns about participants' own health and 33\% about other people's health.

Conclusions During the pandemic lockdown, essential workers (those in healthcare and those providing 'other' essential work) were at increased risk of anxiety compared with those in nonessential work, with those in healthcare also being at increased risk of poor well-being. This highlights the need to recognise the challenges this vital workforce face in pandemics.
Strengths and limitations of this study

- One of the few studies to examine the psychosocial outcomes of the COVID-19 pandemic lockdown, not only in healthcare workers but also those working in 'other' essential roles.

- The study was conducted in New Zealand, which had low rates of COVID-19 infection, which meant that it examined the impact of strict lockdown restrictions in the absence of widespread direct effects of the virus.

- The survey used validated outcome measures and adjusted for confounders; however, the crosssectional design did not allow differentiation between longer term factors and newer impacts deriving from the lockdown.

- Although identifying stressors for different work categories, finer-grained analyses of impacts for specific roles were not possible.

\section{INTRODUCTION}

There is increasing recognition of the psychological impacts of the COVID-19 pandemic and its associated public health restrictions. ${ }^{1-4}$ People employed in essential work, particularly those in healthcare, are consistently identified as being at increased risk of detrimental psychological outcomes. ${ }^{5}$ This paper examines the mental health and well-being of essential workers (those in healthcare and those providing other essential services) during a national lockdown in New Zealand (NZ) at the start of the pandemic.

Previous studies of healthcare workers conducted over early COVID-19 lockdowns report high rates of depression, ${ }^{6}$ anxiety, ${ }^{7}$ distress, ${ }^{68}$ sleep disturbance ${ }^{78}$ and somatic symptoms. ${ }^{7}$ These findings replicate those from previous pandemics, such as the 2002-2004 SARS outbreak, which reported 
significant psychological impacts on healthcare workers. ${ }^{9}$ They may be explained by the multiple stressors those employed in healthcare face in relation to their work, in addition to those experienced by the wider population. These include higher rates of infection, fears of infecting others, working in challenging conditions (with exposure to potentially traumatic events, grief and ethical dilemmas), overwork and stigmatisation. ${ }^{810-12}$

While most people are told to stay at home during a COVID-19 lockdown, workers employed in law enforcement, other emergency services and as providers of essential goods or services (eg, food supply, fuel, waste removal, internet, financial support, transport) are, like healthcare workers,required to keep working. This group has been collectively referred to as 'other' essential workers, to distinguish them from healthcare workers, who, of course, are also essential. In contrast to healthcare workers, there has been only limited research examining the mental health and well-being of these 'other' essential workers. A recent study reported that those employed in roles that involved interacting with the general public were at increased risk of detrimental psychological outcomes. ${ }^{13} \mathrm{~A}$ study of front-line nonmedical workers providing services for patients (eg, security guards, transport staff) also reported high rates of depression, ${ }^{14}$ although another study that compared 'other' essential workers with those in healthcare reported that those in public safety roles (eg, police and emergency personnel) had lower perceived stress than healthcare workers. ${ }^{12}$ It is likely that people employed in 'other' essential work, similar to those in healthcare, may also face increased work demands and feel at increased risk of infection because of potential exposure during their work. Indeed, a recent large study from the UK reported an increased risk of COVID-19 infection in workers in social care, education and transport (in addition to healthcare workers), compared with those in nonessential work. ${ }^{15}$

The first confirmed case of COVID-19 in NZ was on 28 February 2020. On the $21 \mathrm{March}$, a countrywide alert system was announced, with 1 being the lowest and 4 the highest level. The government also released a list of 'essential services', which gave clear guidance to employers and employees for work roles that required people to leave home for work. ${ }^{16}$ On 25 March 2020, NZ moved rapidly to a level 4 lockdown that lasted for 33 days. During this time, all schools and nonessential businesses were shut and nonessential workers required to remain at home. The level 4 lockdown was stringent, with a composite measure rating the public health restrictions in $\mathrm{NZ}$ as being the highest of any World Bank high-income country. ${ }^{17}$ The restrictions were successful with daily case numbers in single figures and falling to zero in the following weeks. ${ }^{18}$ However, at the time the lockdown was implemented, it was not at all certain that the elimination goal would be achieved, and healthcare professionals voiced concern about the potential impacts on the health system. ${ }^{19}$

We have already reported initial data from a survey of a large, demographically representative sample of New
Zealanders. ${ }^{2021}$ The aim of the exploratory study reported here was to use this same survey to compare psychological outcomes, experiences and sources of stress over the COVID-19 lockdown in NZ in essential workers (healthcare workers and 'other' essential workers) with that of other workers employed in nonessential work roles. Understanding the stressors and the mental health and well-being of this vital workforce is important to inform their psychosocial needs. This understanding is particularly pertinent in the global environment with the implementation of further lockdowns and restrictions.

\section{METHODS}

\section{Study design and survey}

This was a cross-sectional survey that could be completed on a mobile phone, tablet or computer and took approximately 15 minutes $^{20}$. All participants provided consent before they could proceed with the survey.

The survey was fielded using the Qualtrics platform between 15 April and 8 May 2020, during the NZ lockdown. Between the start of the pandemic and the launch of the surveys, there were 1366 cases of COVID-19 in NZ and nine deaths. During the survey period, the cases rose by 56 with a further two deaths.

\section{Participants and recruitment}

Potential participants were identified and invited to complete the online survey using three methods of distribution of the same survey. Two methods used national survey panels, the Dynata survey platform (methodology previously described $\mathrm{in}^{20}$ ) and the NZ government's Health and Justice survey panels (methodology previously described ${ }^{22}{ }^{23}$ ). The third used purposive sampling of 711 Facebook contacts of the Medical Research Institute of NZ (MRINZ), who identified as being an essential worker and had consented to receiving invitations to participate in 'COVID-19-related' research, This was to increase the number of essential workers surveyed because they were likely to be under-represented in the panels described above (because they were at work away from their homes).

People were eligible for the survey if they were living in NZ during the study period, were aged 18 years or over at the time of the level 4 lockdown, had an email address and internet connection and provided informed consent to participate. For the purpose of this paper, we selected all those who said they were employed at the time of the survey and excluded from the analyses those who were not.

\section{Measures}

The survey contained three standardised self-report measures of psychological distress(the Kessler Psychological Distress Scale (K10)), ${ }^{24}$ anxiety (the Generalised Anxiety Disorder Scale (GAD-7) $)^{25}$ and well-being (the WHO Well-Being Index (WHO-5) $).{ }^{26}$ The K10 is a 10 -item scale measuring nonspecific symptoms of anxiety 
and depression over the previous 4 weeks. Scores are reported in a 0 to 40 range to align with reporting in the NZ Health Survey, ${ }^{22}$ with people scoring 12 or higher having moderate to high distress. The GAD-7 measures anxiety symptoms with respondents indicating how much they have been bothered by each of 7 symptoms over the last 2 weeks, on a 4-point scale ranging from 'not at all' to 'nearly every day'. Scores range from 0 to 21, with cut-off scores of 10 and higher indicating at least moderate anxiety. The WHO-5 is one of the most widely used scales for assessing subjective psychological well-being. ${ }^{26}$ It contains 5 positively phrased items, with respondents rating each statement for the last 2 weeks. Scores range from 0 to 25 , with cut-off scores of 12 and under indicating poor well-being, and scores greater than 22 indicating excellent well-being. We assessed alcohol consumption by asking participants how many standard drinks they consumed on an average 7-day period before the lockdown and how many standard drinks they had consumed over the previous 7 days.

Respondents were asked to identify whether they were employed, and if employed, whether they were essential workers. If they were in an essential work role, they were asked to identify the type of essential work from one of four categories: healthcare; law enforcement; other emergency services such as fire service; or as a provider of other essential goods or services such as food supply, fuel, waste removal, internet, financial support or transport.

Demographic and prelockdown factors included age, gender, ethnicity, socioeconomic status (education and household income), smoking and alcohol usage, health vulnerability, previous history of mental disorder and prior exposure to a traumatic event. Objective and subjective lockdown experiences were assessed by questions on living circumstances, relationships and connections with others, workload, change in alcohol use, COVID-19 exposure and concerns about risk of infection. Respondents were also asked to identify their main sources of stress during the lockdown (uncertainty about their health or that of a family member, finances, employment, the wider consequences of COVID-19).

The survey questions are available as a supplementary file (online supplemental file 1). A detailed description of survey items and construction of the questionnaire has previously been published. ${ }^{20}$

\section{Patient and public involvement}

No patients were involved. The survey sampled members of the general public. We developed and refined the survey using a peer-review process. ${ }^{27}$ We consulted with government health advisors, people with lived experience of mental distress, experts in survey design and healthcare professionals during the survey development and testing phase. The authors received advice from Māori cultural advisors to ensure culturally appropriate question wording and context for questions specifically concerning Māori. We requested feedback on the survey content, both in terms of the most important outcome measures and on language, clarity, format, length and flow. We made iterative improvements based on the feedback. We then pretested the revised questionnaire on a small sample of the general public and further modified it to address feedback.

\section{Statistical analyses}

This was an exploratory study (hypothesis generating) designed and implemented at the start of the pandemic. As we were not trying to confirm any hypothesis, no sample size calculations were performed; however, we were cognisant of sample size when building statistical models to minimise the risk of overfitting. Responses from all three methods of survey distribution were combined, and analyses were performed on unweighted data. Participants' demographics, socioeconomic characteristics and health histories were summarised by work category using counts and percentages. The proportion of participants reporting poor outcomes on each of the K10, GAD-7 and WHO-5 psychological measures, or reporting increased alcohol usage, was determined by work category and associations assessed using $\chi^{2}$ tests. Differences between work categories were quantified as risk ratios with 95\% CIs, calculated using a series of unadjusted and confounderadjusted Poisson-generalised linear regression models with robust 'sandwich' SEs. ${ }^{28}$ Models were first adjusted by age, gender and ethnicity, and second by other potential confounders considered to have been fixed prior to lockdown (income, smoking status, living alone, health vulnerability, previous history of mental disorder and prior exposure to a traumatic event). Participants' experiences of lockdown were summarised by work category as counts and percentages, and groupwise differences were assessed using $\chi^{2}$ or Fisher's exact tests. Missing data were excluded via listwise deletion. Analysis was performed using the $\mathrm{R}$ programming language and environment ( $\mathrm{R}$ V.4.0.3).

\section{RESULTS}

In total, there were 4393 survey responses. The noncompletion rate, defined as those who opened and started but did not complete the survey before the cut-off time, was $12.0 \%(\mathrm{n}=529)$, producing a cleaned sample of 3864 survey responses. The surveys were completed over a similar time period: $\mathrm{n}=2010$ from the Dynata panel; $\mathrm{n}=1477$ from the government's Health and Justice panels and $n=377$ from the MRINZ sample. Of these, 1369 (35.4\%) were not employed at the time of the survey (and were excluded from this analysis), giving a total of 2495 participants who were in employment and were included in our analyses.

There were some differences between the three samples in terms of the distribution of essential and nonessential workers, primarily reflecting the recruitment of the MRINZ sample from predominantly medical contacts. However, the data were broadly comparable, which allowed the samples to be combined. In view of the small numbers identifying as working in law enforcement $(n=57)$ and other emergency services $(n=43)$, these two categories were combined with 
Table 1 Demographic characteristics of essential and nonessential workers

\begin{tabular}{|c|c|c|c|}
\hline Characteristic & Healthcare essential worker & Other essential worker & Nonessential worker \\
\hline \multicolumn{4}{|l|}{ Gender } \\
\hline Male & $17.4 \%(66)$ & $47.5 \%(306)$ & $43.5 \%(635)$ \\
\hline \multicolumn{4}{|l|}{ Age } \\
\hline $15-24$ & $4.5 \%(17)$ & $7.4 \%(48)$ & $9.1 \%(133)$ \\
\hline $45-54$ & $27.0 \%(103)$ & $25.7 \%(167)$ & $22.3 \%(326)$ \\
\hline $55-64$ & $25.7 \%(98)$ & $19.4 \%(126)$ & $17.3 \%(254)$ \\
\hline $65+$ & $6.0 \%(23)$ & $5.4 \%(35)$ & $8.3 \%(122)$ \\
\hline \multicolumn{4}{|l|}{ Ethnicity (prioritised) } \\
\hline European/Other & $76.6 \%(291)$ & $70.4 \%(456)$ & $70.0 \%(1025)$ \\
\hline \multicolumn{4}{|l|}{ Education } \\
\hline No formal qualification & $5.8 \%(22)$ & $8.9 \%(58)$ & $6.4 \%(94)$ \\
\hline High school & $10.0 \%(38)$ & $25.7 \%(167)$ & $22.3 \%(326)$ \\
\hline Certificate or diploma & $21.0 \%(80)$ & $25.3 \%(164)$ & $25.1 \%(368)$ \\
\hline Bachelor's degree & $22.3 \%(85)$ & $23.1 \%(150)$ & $26.5 \%(388)$ \\
\hline Post-graduate & $40.9 \%(156)$ & $16.9 \%(110)$ & $19.7 \%(289)$ \\
\hline \multicolumn{4}{|l|}{ Income } \\
\hline NZ $\$ 30000$ or less & $8.9 \%(34)$ & $10.7 \%(69)$ & $19 \%(278)$ \\
\hline Health vulnerability & $6.3 \%(24)$ & $5.7 \%(37)$ & $4.0 \%(58)$ \\
\hline History of previous exposure to trauma & $48.0 \%(183)$ & $39.9 \%(259)$ & $28.3 \%(415)$ \\
\hline
\end{tabular}

Data were missing for the following variables (n): gender (12), ethnicity (3), income (4), history of previous exposure to trauma (7).

those providing other essential goods or services. This meant that in the final combined sample, there were three work categories for comparison; essential workers in healthcare $(\mathrm{n}=381)$, 'other' essential workers $(\mathrm{n}=649)$ and workers in nonessential work $(\mathrm{n}=1465)$.

\section{Demographic and socioeconomic characteristics}

Table 1 shows the demographic profile of survey respondents by the three work categories. Healthcare workers were predominantly female, whereas those from the two other categories showed a more balanced gender distribution. A previous history of a mental health disorder was noted in $26 \%$ of healthcare workers, $23 \%$ of 'other' essential workers and $19 \%$ of nonessential workers. A history of exposure to previous trauma was noted in $48 \%$ of healthcare workers, $40 \%$ of 'other' essential workers and $28 \%$ of nonessential workers. The most common trauma was exposure to a natural disaster, which was reported by a total of $17 \%$ of the sample.

\section{Psychological distress, anxiety and well-being}

The unadjusted risk ratios for psychological distress, anxiety and well-being are summarised in table 2 . The results show that about a quarter of all workers scored above the cut-off for moderate to severe psychological distress $(\mathrm{K} 10>12)$, and that those in essential work (healthcare and 'other' essential work) were not at greater risk of reporting moderate-high levels of psychological distress than those in nonessential work $(p=0.153)$. Essential workers (healthcare and 'other' essential workers) were however, at an estimated $61 \%$ greater risk than nonessential workers of reporting moderate-high levels of anxiety from the GAD-7 $(p=<0.001)$. Healthcare workers, but not 'other' essential workers, were at an estimated $15 \%$ 
Table 2 Unadjusted and adjusted rates of psychological distress, anxiety and poor well-being

\begin{tabular}{|c|c|c|c|c|}
\hline & $\%$ (number) & Risk ratio (95\% Cl) & Adjusted risk ratio* & Adjusted risk ratiof \\
\hline \multicolumn{5}{|l|}{$K 10 \geq 12$} \\
\hline Nonessential worker & $22.3(326)$ & 1.00 & 1.00 & 1.00 \\
\hline Other essential workers & $26.1(169)$ & $\begin{array}{l}1.17 \\
(0.99 \text { to } 1.37)\end{array}$ & $\begin{array}{l}1.17 \\
(1.00,1.37)\end{array}$ & $\begin{array}{l}1.12 \\
(0.92 \text { to } 1.37)\end{array}$ \\
\hline Nonessential worker & $9.8(143)$ & 1.00 & 1.00 & 1.00 \\
\hline Healthcare workers & $15.7(60)$ & $\begin{array}{l}1.61 \\
(1.22 \text { to } 2.13)\end{array}$ & $\begin{array}{l}1.89 \\
(1.43,2.50)\end{array}$ & $\begin{array}{l}1.71 \\
\text { (1.29 to } 2.27)\end{array}$ \\
\hline Other essential workers & $15.7 \%(102)$ & $\begin{array}{l}1.61 \\
(1.27 \text { to } 2.04)\end{array}$ & $\begin{array}{l}1.62 \\
(1.28,2.05)\end{array}$ & $\begin{array}{l}1.59 \\
(1.25 \text { to } 2.02)\end{array}$ \\
\hline Healthcare workers & $51.2(195)$ & $\begin{array}{l}1.15 \\
(1.03 \text { to } 1.29)\end{array}$ & $\begin{array}{l}1.21 \\
(1.05,1.41)\end{array}$ & $\begin{array}{l}1.19 \\
(1.02 \text { to } 1.39)\end{array}$ \\
\hline Other essential workers & $48.2(312)$ & $\begin{array}{l}1.08 \\
(0.98 \text { to } 1.20)\end{array}$ & $\begin{array}{l}1.08 \\
(0.95,1.23)\end{array}$ & $\begin{array}{l}1.07 \\
(0.94 \text { to } 1.22)\end{array}$ \\
\hline \multicolumn{5}{|l|}{ Alcohol increase } \\
\hline Nonessential worker & $30.3(443)$ & 1.00 & 1.00 & 1.00 \\
\hline Healthcare workers & $33.9(129)$ & $\begin{array}{l}1.12 \\
(0.95 \text { to } 1.32)\end{array}$ & $\begin{array}{l}1.03 \\
(0.87,1.21)\end{array}$ & $\begin{array}{l}1.04 \\
\text { (0.88 to } 1.23)\end{array}$ \\
\hline Other essential workers & $33.3(216)$ & $\begin{array}{l}1.10 \\
(0.96 \text { to } 1.26)\end{array}$ & $\begin{array}{l}1.08 \\
(0.95,1.23)\end{array}$ & $\begin{array}{l}1.06 \\
(0.93 \text { to } 1.21)\end{array}$ \\
\hline
\end{tabular}

Data were missing for the following variables (n): K10 (6), GAD-7 (2), WHO-5 (6), alcohol (4)

*Adjusted for age, gender and ethnicity.

†Adjusted for age, gender, ethnicity, income, smoking status, living alone, health vulnerability, prior mental health and prior exposure to a traumatic event.

GAD-7, Generalised Anxiety Disorder Assessment; K10, Kessler Psychological Distress Scale; WHO-5, WHO Well-Being Index.

greater risk than nonessential workers of reporting poor well-being from the WHO-5 ( $\mathrm{p}=0.038)$. About one-third of all workers increased their use of alcohol but those in essential work (healthcare and 'other' essential work) were not at greater risk of this than nonessential workers $(\mathrm{p}=0.212)$.

Potential confounders included age, gender, ethnicity, socioeconomic status, living alone, health vulnerability, previous history of mental disorder and exposure to previous trauma. As shown in table 2, after controlling for potential confounders, those in healthcare were at $71 \%$ greater risk, and those in 'other' essential work at $59 \%$ greater risk of reporting at least moderate levels of anxiety (GAD-7 $\geq 10$ ) than nonessential workers. Healthcare workers were at $19 \%$ greater risk of poor well-being (WHO-5 <13). There was no evidence of a difference across the work roles in risk for psychological distress $(\mathrm{K} 10 \geq 12)$ or increased alcohol use.

\section{Positive outcomes}

In addition to detrimental psychological outcomes, we were also interested in those who reported excellent well-being during the lockdown (WHO-5 $\geq 22$ ). Healthcare workers had a lower likelihood of this than nonessential workers (risk ratio $=0.5395 \%$ CI $0.31,0.89, p=0.007$ ); $3.9 \%$ of healthcare workers, $9.0 \%$ of 'other' essential workers and $7.5 \%$ of nonessential workers reported excellent well-being.

\section{Living circumstances, connections, workload and COVID-19 testing}

As shown in table 3, there were differences across the work categories in terms of maintaining contact with family and friends outside of their bubble-the people respondents were living with over the lockdown-(which included contact by video link, telephone, email or letter), with $36 \%$ of healthcare workers, $34 \%$ of nonessential workers and $29 \%$ of 'other' essential workers reporting decreased contact compared with prelockdown $(p=0.008)$. Those in essential work reported greater rates of increased workload than nonessential workers $(p<0.001)$. Those in healthcare reported higher rates of COVID-19 testing compared with the other work roles, with $12 \%$ having been tested for COVID-19. Although the 
Table 3 Living circumstances, social connections, workload and COVID-19 testing

\section{Living circumstances, social connections, work demand and COVID-19 testing}

\section{Other essential}

Healthcare worker worker
Nonessential worker

Living circumstances

Living situation

$\begin{array}{llll}\text { Living alone } & 15.0 \%(57) & 13.9 \%(90) & 12.2 \%(179) \\ \text { With one adult } & 24.7 \%(94) & 29.3 \%(190) & 28.9 \%(423) \\ \text { With other adults } & 24.5 \%(93) & 17.3 \%(112) & 20.4 \%(298) \\ \text { With children } & 35.8 \%(136) & 39.6 \%(257) & 38.5 \%(564)\end{array}$

Satisfaction with 'bubble' (defined as the people respondents were living with over the lockdown)

$\begin{array}{lcrr}\text { Extremely dissatisfied } & 3.4 \%^{13} & 3.9 \%^{25} & 3.5 \%(51) \\ \text { Dissatisfied } & 2.6 \%^{10} & 2.9 \%{ }^{19} & 1.8 \%{ }^{27} \\ \text { Neither satisfied nor dissatisfied } & 6.6 \%^{25} & 8.9 \%(58) & 8.5 \%(124) \\ \text { Satisfied } & 28.3 \%(108) & 32.8 \%(213) & 31.1 \%(455) \\ \text { Extremely satisfied } & 59.1 \%(225) & 51.5 \%(334) & 55.2 \%(808)\end{array}$

Getting along with members of household

\begin{tabular}{|c|c|c|c|c|}
\hline Very badly & $1.2 \%{ }^{4}$ & $0.5 \%^{3}$ & $0.6 \%^{8}$ & 0.68 \\
\hline Badly & $2.8 \%^{9}$ & $3.4 \%{ }^{19}$ & $2.1 \%(27)$ & \\
\hline Neither well nor badly & $11.1 \%^{36}$ & $12.0 \%(67)$ & $11.1 \%(143)$ & \\
\hline Very well & $41.7 \%(135)$ & $43.8 \%(245)$ & $45.15(579)$ & \\
\hline \multicolumn{5}{|c|}{ Change in contact with others outside bubble } \\
\hline Stayed the same or increased & $63.9 \%(241)$ & $71.2 \%(461)$ & $66.4 \%(968)$ & \\
\hline \multicolumn{5}{|l|}{ Feeling lonely or isolated } \\
\hline All of the time & $2.6 \%{ }^{10}$ & $3.2 \%{ }^{21}$ & $1.8 \%^{26}$ & 0.53 \\
\hline Most of the time & $4.7 \%{ }^{18}$ & $4.9 \%{ }^{32}$ & $4.7 \%(69)$ & 0.53 \\
\hline Some of the time & $19.7 \%(75)$ & $21.9 \%(142)$ & $21.7 \%(318)$ & \\
\hline \multicolumn{5}{|l|}{ Work } \\
\hline Workload increased & $31.8 \%(121)$ & $25.8 \%(167)$ & $17.2 \%(252)$ & $<0.001$ \\
\hline Less paid work & $20.5 \%(78)$ & $23.6 \%(153)$ & $40.5 \%(594)$ & $<0.001$ \\
\hline \multicolumn{5}{|l|}{ COVID-19 } \\
\hline \multicolumn{5}{|l|}{ Having a COVID-19 test } \\
\hline Tested & $11.6 \%{ }^{44}$ & $4.8 \%{ }^{31}$ & $3.1 \%{ }^{45}$ & $<0.001$ \\
\hline Not tested & $88.4 \%(336)$ & $95.2 \%(918)$ & $96.9 \%(1420)$ & $<0.001$ \\
\hline
\end{tabular}

Data were missing for the following variables (n): living circumstances (2), feeling lonely or isolated (1), change in contact (12), work (1), COVID-19 (1)

numbers of confirmed positive tests were low (that is, a total of nine positive tests in the samples), this included four healthcare workers, which represented $1 \%$ of healthcare respondents (Fisher's exact, $\mathrm{p}=0.015$ ).

\section{Main sources of stress}

About $15 \%$ of participants had concerns about their own health and 33\% concerns about other people's health, with no difference by work category $(\mathrm{p}=0.45$ and $\mathrm{p}=0.19$, respectively). Essential workers were less likely to report uncertainty about finances than nonessential workers (healthcare workers 22\%, 'other' essential workers $29 \%$ and nonessential workers $37 \%, \mathrm{p}<0.001)$. There was a similar pattern regarding concerns about employment (healthcare workers 14\%, 'other' essential workers $24 \%$ and nonessential workers $31 \%, \mathrm{p}<0.001)$. Healthcare workers were at greater risk of reporting stress in relation 
to the wider consequences of COVID-19 (healthcare workers $60 \%$, 'other' essential workers $50 \%$ and nonessential workers $53 \%, \mathrm{p}=0.012$ ).

\section{DISCUSSION}

The aim of this study was to compare psychological outcomes, experiences and sources of stress during the COVID-19 lockdown among NZ essential workers with those of other workers employed in nonessential roles. While most essential workers coped well, some did not. Essential workers (both those in healthcare and those providing other essential work) were at increased risk of anxiety compared with nonessential workers. In addition, healthcare workers (but not 'other' essential workers) were at increased risk of poor well-being. Although rates of psychological distress were well above baseline general population measures, ${ }^{29}$ there were no significant differences between the work groups. There was also no difference in rates of increased use of alcohol across the work categories.

\section{Healthcare workers}

The rates of moderate anxiety $(16 \%)$ and moderate to high psychological distress $(25 \%)$ in healthcare workers in our study are at the lower range of those reported internationally $(26 \%-30 \% \text { and } 34 \%-36 \% \text {, respectively })^{5}$. It is likely that this reflects the comparatively low rates of infection and mortality in NZ at the time of data collection. In general, lower rates of anxiety and depression in healthcare workers have been reported from countries where death rates were relatively $\operatorname{low}^{31}$ or where there was an aggressive surveillance programme. ${ }^{32}$

Our study found that healthcare workers had higher anxiety and poorer well-being than nonessential workers during the COVID-19 pandemic lockdown in NZ. To date, while studies have consistently identified healthcare workers as being at increased risk of psychological impacts in pandemics, ${ }^{5}$ mixed findings have been reported in comparison with other workers (rather than the general population); one study increased anxiety ${ }^{123}$ and another reduced anxiety ${ }^{31}$ in healthcare workers compared with 'other' essential workers.

The extant literature suggests that even before the COVID-19 pandemic, healthcare work and associated work-related stress factors could lead to burnout, depression, anxiety, sleep disorders or other psychiatric disorders. ${ }^{34-36}$ In the context of the COVID-19 pandemic, significant additional challenges include increased risk of infection because of potential exposure, workload demands and challenges (with exposure to potentially traumatic events, grief and ethical dilemmas) and social change including stigmatisation. Some or all of these factors may be associated with detrimental psychological outcomes. ${ }^{37}$ Our study attempted to explore some of these issues in NZ where infection and mortality rates have been low by international standards. ${ }^{18}$ Healthcare workers were more likely to have been tested for, and tested positive for, COVID-19. These findings reflect the international literature ${ }^{38}$ and the $\mathrm{NZ}$ context at the time of the survey, where one in 10 cases of COVID-19 were in healthcare workers. ${ }^{39}$ Compared with nonessential workers, healthcare workers were also more likely to report experiencing increased workload and less likely to report concern about finances and employment than nonessential workers. Social isolation has been consistently identified as a risk factor for negative psychological impacts, ${ }^{40}$ and although not different from nonessential workers, about one-third of healthcare workers reported decreased contact with family and friends outside of their 'bubble'. This included not just face-to-face contact (which was reduced for everyone), but contact by video link, telephone, email or letter.

\section{Other essential workers}

Our findings show that, in comparison with nonessential workers, 'other' essential workers were also at increased risk of reporting at least moderate anxiety. Similar to those in healthcare, 'other' essential workers may face increased work demands and feel at increased risk of infection because of potential exposure during their work. Our findings suggest that these workers were also at greater risk of experiencing increased workload and less likely to report concern about finances and employment compared with nonessential workers. Interestingly, they were at less risk of reducing their social contact compared with nonessential workers. This may have impacted on well-being because it is established that social connectedness promotes well-being. ${ }^{41}$

Although there is only a limited literature on psychological outcomes of the pandemic lockdown in 'other' essential workers (because this is effectively a pandemic work grouping), this literature suggests that type of work may be important. Studies have shown that having a role involving construction, manufacture, food retail and transport is associated with reduced well-being ${ }^{42}$ and that medical volunteers or those in medical, nonpatient facing work report high rates of depression. ${ }^{14}$ However, workers in public safety roles (eg, police and emergency personnel) have reported lower levels of perceived stress (compared with healthcare workers). ${ }^{12}$

\section{Importance of feeling safe}

All worker categories reported concern about the safety of themselves, their family and friends, highlighting how crucial this is for most people. It is established that a lack of perceived safety increases the risk of anxiety, depression and Post traumatic stress disorder (PTSD), ${ }^{40}$ and that improving this, through access to personal protective equipment and training, mitigates detrimental psychological outcomes. ${ }^{43}$ It also underpins the established evidence for feelings of safety being associated with resilient outcomes after disasters. ${ }^{41}$

\section{The NZ context}

The NZ Government's COVID-19 'elimination strategy' has been praised internationally, with NZ having had low 
case rates and mortality ${ }^{44}$ (to date 26 deaths). Even at the time the survey was conducted, the strategy was showing positive results. This meant that we examined the impact of strict lockdown restrictions in the absence of widespread direct effects of the virus that may limit the generalisability of the findings to settings in countries where there has been much higher morbidity and mortality.

\section{Limitations and strengths}

Like all survey-based research, our study has some limitations. Outcomes were participants' subjective reports of their experiences and emotions, and while this is not equivalent to a structured diagnostic interview, ${ }^{45}$ it does allow comment on levels of distress. We did not ask respondents about other factors that may have been important such as the meaningfulness of their work ${ }^{46}$ or how they might deal with moral dilemmas (which has been a concern in countries with high mortality). ${ }^{12}$ The data were cross-sectional, and the lack of pre-COVID-19 benchmarks means we cannot determine if our results were indicative of changes resulting from the pandemic (and/or the lockdown response) rather than being more general differences between these groups of workers. However, we were able to adjust for some potential underlying confounders (eg, income, history of mental illness, physical health vulnerability). While we did try and achieve a representative sample, there may have been some selection bias related to over-representation of those with higher socioeconomic status and education, access to a computer/mobile phone or for whom the topic of wellbeing had particular salience (perhaps because they were experiencing difficulties). The use of purposive sampling (through contacts of the MRINZ) to increase the number of essential workers from around NZ may also have introduced selection bias. Overall, however, the demographics (age, ethnicity and close for gender) broadly match the NZ population. There is a slight female preponderance (women more likely to answer surveys) but not to the same extent as seen in many other surveys. ${ }^{47}$ Other limitations relate to the grouping of essential workers into two broad categories, healthcare workers versus 'other' essential workers, which was done because of the small numbers involved (eg, only $\mathrm{n}=100$ respondents in emergency services and law enforcement). This meant that finer-grained analyses were not possible within healthcare (eg, unable to disaggregate type of healthcare role) or within different types of 'other' essential work.

Nevertheless, a strength of our study is that it is one of the few to examine the psychosocial outcomes in those working in nonhealthcare essential roles. Other strengths are that the survey was peer reviewed during development and pretested on members of the general public and used validated outcome measures wherever possible.

\section{CONCLUSIONS}

Our study reports on the mental health and well-being of essential workers during the NZ lockdown, early in the
COVID-19 pandemic. While most essential workers coped well, some did not. Essential workers as a category (both those in healthcare and those providing other eseential work) were at increased risk of anxiety compared with those employed in nonessential work, with those in healthcare also being at increased risk of poor wellbeing. It is important that employers and organisations recognise the challenges this vital workforce face in times of pandemics and implement appropriate support for these workers. We suggest that this support spans a range of domains: ensuring people have adequate protections around being able to work safely; that they have access to accurate information and training and that their workload is manageable. Communication should promote the importance of social connections, and appropriate psychological interventions should be facilitated. We also suggest ongoing collection of robust mental health data to guide these approaches.

\section{Author affiliations}

${ }^{1}$ Department of Psychological Medicine, University of Otago, Christchurch, New Zealand

${ }^{2}$ Department of Population Health, University of Otago, Christchurch, New Zealand ${ }^{3}$ Department of Public Health, University of Otago, Wellington, New Zealand ${ }^{4}$ Department of Psychological Medicine, University of Otago, Wellington, New Zealand

${ }^{5}$ Department of Psychological Medicine, University of Otago, Dunedin, New Zealand

Acknowledgements We would like to thank Dynata, NZ Ministry of Health, Ministry of Justice, Department of Statistics and Irene Braithwaite from the MRINZ for their generous support of this research. We also thank Janet Hoek, Anaru Waa, Emma Sutich, Marcellus Paki, Fiona Mathieson, Giles Newton-Howes and Elliot Bell for expert advice on survey content and design.

Contributors CB roles methodology, writing—original draft, writing—review and editing. JW roles data curation, formal analysis, writing — review and editing. BB roles methodology, writing — review and editing. JS roles data curation, formal analysis, resources, writing — review and editing. MJ roles conceptualisation, investigation, methodology, project administration, resources, writing —original draft, writing — review and editing. PG roles conceptualisation, investigation, methodology, supervision, writing — review and editing. CR roles methodology, writing - review and editing. SE-P roles conceptualisation, data curation, investigation, methodology, project administration, resources, supervision, writing — review and editing

Funding The authors have not declared a specific grant for this research from any funding agency in the public, commercial or not-for-profit sectors.

Competing interests None declared.

Patient consent for publication Not required.

Ethics approval The study was approved by the University of Otago Human Ethics Committee (approval code F20/003) and underwent Māori consultation with the Ngāi Tahu Research Committee.

Provenance and peer review Not commissioned; externally peer reviewed.

Data availability statement Data are available upon reasonable request. Deidentified participant data for participants from the three surveys analysed are available from [Caroline Bell; caroline.bell@otago.ac.nz]

Supplemental material This content has been supplied by the author(s). It has not been vetted by BMJ Publishing Group Limited (BMJ) and may not have been peer-reviewed. Any opinions or recommendations discussed are solely those of the author(s) and are not endorsed by BMJ. BMJ disclaims all liability and responsibility arising from any reliance placed on the content. Where the content includes any translated material, BMJ does not warrant the accuracy and reliability of the translations (including but not limited to local regulations, clinical guidelines, terminology, drug names and drug dosages), and is not responsible for any error and/or omissions arising from translation and adaptation or otherwise. 
Open access This is an open access article distributed in accordance with the Creative Commons Attribution Non Commercial (CC BY-NC 4.0) license, which permits others to distribute, remix, adapt, build upon this work non-commercially, and license their derivative works on different terms, provided the original work is properly cited, appropriate credit is given, any changes made indicated, and the use is non-commercial. See: http://creativecommons.org/licenses/by-nc/4.0/.

ORCID iD

James Stanley http://orcid.org/0000-0002-8572-1047

\section{REFERENCES}

1 Adhanom Ghebreyesus T. Addressing mental health needs: an integral part of COVID -19 response. World Psychiatry 2020;19:129-30.

2 Holmes EA, O'Connor RC, Perry VH, et al. Multidisciplinary research priorities for the COVID-19 pandemic: a call for action for mental health science. Lancet Psychiatry 2020;7:547-60.

3 Xiong J, Lipsitz O, Nasri F, et al. Impact of COVID-19 pandemic on mental health in the general population: a systematic review. J Affect Disord 2020;277:55-64.

4 da Silva ML, Rocha RSB, Buheji M, et al. A systematic review of the prevalence of anxiety symptoms during coronavirus epidemics. $J$ Health Psychol 2021;26:115-25.

5 Krishnamoorthy Y, Nagarajan R, Saya GK, et al. Prevalence of psychological morbidities among general population, healthcare workers and COVID-19 patients amidst the COVID-19 pandemic: a systematic review and meta-analysis. Psychiatry Res 2020;293:113382.

6 Chew NWS, Lee GKH, Tan BYQ, et al. A multinational, multicentre study on the psychological outcomes and associated physical symptoms amongst healthcare workers during COVID-19 outbreak. Brain Behav Immun 2020;88:559-65.

7 Zhang W-R, Wang K, Yin L, et al. Mental health and psychosocial problems of medical health workers during the COVID-19 epidemic in China. Psychother Psychosom 2020;89:242-50.

8 Lai J, Ma S, Wang Y, et al. Factors associated with mental health outcomes among health care workers exposed to coronavirus disease 2019. JAMA Netw Open 2020;3:e203976.

9 Wu P, Fang Y, Guan Z, et al. The psychological impact of the SARS epidemic on hospital employees in China: exposure, risk perception, and altruistic acceptance of risk. Can J Psychiatry 2009;54:302-11.

10 Kang L, Li Y, Hu S, et al. The mental health of medical workers in Wuhan, China dealing with the 2019 novel coronavirus. Lancet Psychiatry 2020;7:e14.

11 Shanafelt T, Ripp J, Trockel M. Understanding and addressing sources of anxiety among health care professionals during the COVID-19 pandemic. JAMA 2020;323:2133-4

12 Mazza M, Attanasio M, Pino MC, et al. Moral decision-making, stress, and social cognition in frontline workers vs. population groups during the COVID-19 pandemic: an explorative study. Front Psychol 2020;11:588159.

13 Robillard R, Saad M, Edwards J, et al. Social, financial and psychological stress during an emerging pandemic: observations from a population survey in the acute phase of COVID-19. BMJ Open 2020;10:e043805.

14 Fang X, Zhang J, Teng C, et al. Depressive symptoms in the front-line non-medical workers during the COVID-19 outbreak in Wuhan. J Affect Disord 2020;276:441-5.

15 Karlsson U, Fraenkel CJ. Covid-19: risks to healthcare workers and their families.. BMJ 2020;371:m3944.

16 Government NZ. National Crisis Management Centre Nationa Action Plan. In: National Crisis Management Centre. Wellington, New Zealand: New Zealand Government, 2020.

17 Hale TW S, Anna P, Phillips T, et al. Oxford COVID-19 government response Tracker. Blavatnik School of Government OU, editor, 2020.

18 Cousins S. New Zealand eliminates COVID-19. Lancet 2020;395:1474.

19 Covid-19 coronavirus: Top intensive care doctor admits he is scared New Zealand Herald, 2020 [Accessed 24 Mar 2020].

20 Every-Palmer S, Jenkins M, Gendall P, et al. Psychological distress, anxiety, family violence, suicidality, and wellbeing in New Zealand during the COVID-19 lockdown: a cross-sectional study. PLoS One 2020;15:e0241658.

21 Jenkins M, Hoek J, Jenkin G, et al. Silver linings of the COVID-19 lockdown in New Zealand. PLoS One 2021;16:e0249678.

22 NZ Ministry of Health. Methodology report 2019/20: new Zealand health survey. Wellington, New Zealand: New Zealand Ministry of Health, 2020.
23 NZ Ministry of Justice. New Zealand crimes and victims survey; methodology report. Wellington, New Zealand: New Zealand Ministry of Justice, 2018.

24 Kessler RC, Barker PR, Colpe LJ, et al. Screening for serious mental illness in the general population. Arch Gen Psychiatry 2003;60:184-9.

25 Spitzer RL, Kroenke K, Williams JBW, et al. A brief measure for assessing generalized anxiety disorder: the GAD-7. Arch Intern Med 2006;166:1092-7.

26 Topp CW, Østergaard SD, Søndergaard S, et al. The WHO-5 well-being index: a systematic review of the literature. Psychother Psychosom 2015;84:167-76.

27 Bradburn NW, Brain; Sudman S. Asking questions : the definitive guide to questionnaire design - for market research, political polls, and social and health questionnaires. San Francisco, USA: JosseyBass, 2004.

28 Zou G. A modified poisson regression approach to prospective studies with binary data. Am J Epidemiol 2004;159:702-6.

29 Oakley Browne MA, Wells JE, Scott KM, et al. The Kessler psychological distress scale in te Rau Hinengaro: the New Zealand mental health survey. Aust N Z J Psychiatry 2010;44:314-22.

30 Salazar de Pablo G, Vaquerizo-Serrano J, Catalan A, et al. Impact of coronavirus syndromes on physical and mental health of health care workers: systematic review and meta-analysis. J Affect Disord 2020;275:48-57.

31 Skoda E-M, Teufel M, Stang A, et al. Psychological burden of healthcare professionals in Germany during the acute phase of the COVID-19 pandemic: differences and similarities in the International context. J Public Health 2020:42:688-95.

32 Chew NWS, Ngiam JN, Tan BY-Q, et al. Asian-Pacific perspective on the psychological well-being of healthcare workers during the evolution of the COVID-19 pandemic. BJPsych Open 2020;6:e116.

33 Maciaszek J, Ciulkowicz M, Misiak B, et al. Mental health of medical and non-medical professionals during the peak of the COVID-19 pandemic: a cross-sectional nationwide study. J Clin Med 2020;9. doi:10.3390/jcm9082527. [Epub ahead of print: 0508 2020].

$34 \mathrm{Kim}$ M-S, Kim T, Lee D, et al. Mental disorders among workers in the healthcare industry: 2014 National health insurance data. Ann Occup Environ Med 2018;30:31.

35 Ahola $\mathrm{K}$, Honkonen $\mathrm{T}$, Isometsä $\mathrm{E}$, et al. The relationship between job-related burnout and depressive disorders--results from the Finnish Health 2000 Study. J Affect Disord 2005;88:55-62.

36 Wall TD, Bolden RI, Borrill CS, et al. Minor psychiatric disorder in NHS trust staff: occupational and gender differences. $\mathrm{Br} J$ Psychiatry 1997:171:519-23.

37 Cipolotti L, Chan E, Murphy P. Factors contributing to the distress, concerns, and needs of UK neuroscience health care workers during the COVID-19 pandemic. Psychology and Psychotherapy: Theory, Research and Practice:e12298.

38 Mutambudzi M, Niedwiedz C, Macdonald EB, et al. Occupation and risk of severe COVID-19: prospective cohort study of 120075 UK Biobank participants. Occup Environ Med 2020. doi:10.1136/ oemed-2020-106731. [Epub ahead of print: 09 Dec 2020].

39 H D. Coronavirus: Healthcare workers make up 1 in 10 of New Zealand's COVID-19 cases. Stuff, New Zealand [Accessed 30 April 2020].

40 Serrano-Ripoll MJ, Meneses-Echavez JF, Ricci-Cabello I, et al. Impact of viral epidemic outbreaks on mental health of healthcare workers: a rapid systematic review and meta-analysis. J Affect Disord 2020;277:347-57.

41 Hobfoll SE, Stevens NR, Zalta AK. Expanding the science of resilience: conserving resources in the aid of adaptation. Psychol Inq 2015;26:174-80.

42 Chen DT-H, Wang Y-J. Inequality-Related health and social factors and their impact on well-being during the COVID-19 pandemic: findings from a national survey in the UK. Int J Environ Res Public Health 2021;18. doi:10.3390/ijerph18031014. [Epub ahead of print: $24012021]$.

43 Brooks SK, Dunn R, Amlôt R, et al. A systematic, thematic review of social and occupational factors associated with psychological outcomes in healthcare employees during an infectious disease outbreak. J Occup Environ Med 2018;60:248-57.

44 Baker MG, Wilson N, Anglemyer A. Successful elimination of Covid-19 transmission in New Zealand. N Engl J Med 2020;383:e56.

45 Levis B, Yan XW, He C, et al. Comparison of depression prevalence estimates in meta-analyses based on screening tools and rating scales versus diagnostic interviews: a meta-research review. BMC Med 2019;17:65.

46 Ruiz-Frutos C, Ortega-Moreno M, Allande-Cussó R, et al. Sense of coherence, engagement, and work environment as precursors of psychological distress among non-health workers during the COVID-19 pandemic in Spain. Saf Sci 2021;133:105033. 
